\title{
Solidification Behaviour and the Evolution of Microstructure in the Laser Cladding of Aluminium on Magnesium Substrate
}

\author{
T. M. Yue and T. Li \\ The Advanced Manufacturing Technology Research Centre, Department of Industrial and Systems Engineering, \\ The Hong Kong Polytechnic University, Hung Hom, Hong Kong, P. R. China
}

Laser cladding of aluminium powders was performed on pure magnesium substrates using the blown powder method. The microstructure across the laser-clad track was studied. Starting from the bottom of the laser-clad to the top surface of the track, a series of microstructures was observed: a planar growth interface of the substrate, a narrow band of $(\beta+\gamma)$ eutectic, a narrow band of $\beta$ cellular structure, and finally a relatively thick layer of $\alpha$-Al and $(\alpha+\beta)$ eutectic structure. The evolution of the various phases and microstructures is discussed in terms of the distribution of solute in conjunction with the Al-Mg phase diagram, temperature gradient and solidification rate, constitutional supercooling theory, and the condition for columnar-to-equiaxed crystal transition. [doi:10.2320/matertrans.48.1064]

(Received December 11, 2006; Accepted February 27, 2007; Published April 25, 2007)

Keywords: laser cladding, solidification, interface stability, equiaxed crystal, cellular structure

\section{Introduction}

The ever increasing demand for light-weight materials for engineering applications, especially for the aerospace and automobile industries makes the development of magnesiumbased materials with improved properties a pressing issue. Notwithstanding the advances that have been made in alloy development, magnesium alloys still suffer from the inherently undesirable properties of poor corrosion and wear resistance, which seriously impede the wider application of the alloys. Over the years, intensive research efforts have been devoted to overcoming these shortcomings. High-power laser cladding, a surface engineering technique, has shown great potential for improving the surface properties of magnesium alloys. ${ }^{1-4)}$ An essential factor for the success of laser cladding is the achievement of a strong metallurgical bond over the entire interface between the substrate and the clad-layer. It is understood that the formation of a strong bond between the clad and the substrate is chiefly governed by the solidification condition and behaviour at the interface between the two. Moreover, the properties of the clad-layer relate largely to its grain structure. Therefore a good understanding of the solidification behaviour of the lasermelt zone is vital.

The results of previous research studies on the laser cladding of various metals on Mg-based substrate have indeed provided valuable information on the solidification behaviour of the clad-layer. The early work of Subramanian and Wang on laser cladding of $\mathrm{Mg}-\mathrm{Zr}$ and $\mathrm{Mg}$ - $\mathrm{Al}$ alloys on magnesium substrates ${ }^{1,2)}$ resulted in some useful information in relating laser-cladding parameters to microstructure and corrosion properties. It was reported that ${ }^{2)}$ the improved corrosion resistance of the $\mathrm{Mg}-\mathrm{Al}$ cladded magnesium substrate was due to the presence of a randomly oriented polycrystalline structure. However, the work did not analyse the evolution of the polycrystalline structure. Similar work was performed by Majumdar, ${ }^{5,6)}$ where systematic studies were conducted on the laser surface treatment of $\mathrm{Mg}$-based alloys, with different alloying elements, for improving the corrosion resistance of the magnesium substrate. More recently, Ignat ${ }^{7)}$ studied the laser cladding of aluminium on magnesium alloys WE43 and ZE41. The resulting microstructure was analysed and some mechanical properties were determined. Nonetheless, most of these previous works focussed mainly on revealing the influences of laser processing parameters upon microstructure with much effort spent on the characterisation and identification of the phases present in the laser-clad coating. Notwithstanding the contributions of these studies, it is considered that our understanding on the solidification behaviour and phase evolution in laser cladding of protective layers on Mg-based materials is still far from satisfactory, especially in modelling the evolution of microstructure. With this background in mind, the present research aims to study the solidification behaviour and phase evolution in the laser cladding of aluminium on magnesium substrate using the constitutional supercooling theory and the columnar-to-equiaxed transition model.

\section{Experimental Method}

Commercially pure aluminium powder was laser cladded onto a commercially pure cast magnesium substrate $(30 \times$ $30 \times 10 \mathrm{~mm}$, purity $>99.9$ mass \%) using a one-step blown powder method. The surface of the substrate was cleaned by sandblasting prior to laser cladding. In order to eliminate any water that may be trapped in the powder, the specimens were dried in a vacuum oven for 24 hours. The cladding experiment was conducted in a laser rapid forming system that consisted of a $5 \mathrm{~kW}$ continuous wave $\mathrm{CO}_{2}$ laser from Rofin Sinar, a four-axis numerical control working table, and a powder feeder with a lateral nozzle. The experiment was conducted inside a chamber, the atmosphere of which was controlled. The laser was mounted on an overhead carriage and the beam was directed into the chamber through a window on top of it. The controlled-atmosphere chamber was filled with argon gas, and argon gas was also used to deliver the metal powder to prevent the molten pool from oxidizing and oxide contamination from occurring during processing. The laser beam was directed onto the substrate to create a shallow molten pool and at the same time aluminium powder 


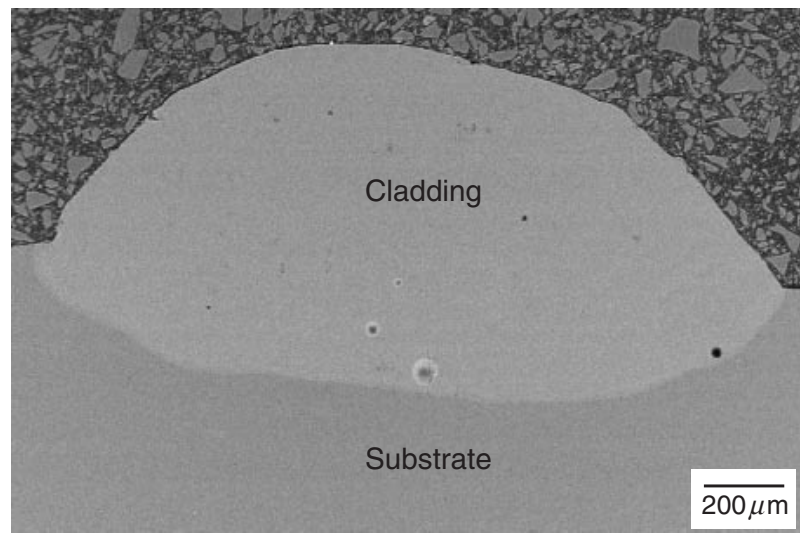

Fig. 1 A SEM backscattered electron image of a transverse section of laser-cladding.

was delivered into the pool using a lateral powder feeder. The metal powder was melted and subsequently re-solidified to form the laser-clad track. The powder was delivered to the molten pool by an argon jet with a metal flow rate of 83 $\mathrm{cm}^{3} / \mathrm{s}$. When using such a system, the thickness and the profile of the track can be easily controlled. The laser beam was focused to a spot of $1.4 \mathrm{~mm}$. The laser scanning rate was $5 \mathrm{~mm} / \mathrm{s}$ and the laser power employed was $2 \mathrm{~kW}$. Using these conditions, single tracks with a thickness of about $0.8 \mathrm{~mm}$ were produced.

The specimens for microscopic study were ground with a series of emery papers and then polished with $1 \mu \mathrm{m}$ diamond abrasives. The microstructure of the material was revealed using an etchant of $5 \mathrm{cc}$ acetic acid, $6 \mathrm{~g}$ picric acid, $10 \mathrm{cc}$ water, and $100 \mathrm{cc}$ ethanol (95\%). The microstructure and phases of the laser-clad tracks were characterized using a Leica microscope, a Philips XRD System, and a Leica scanning electron microscope equipped with energy dispersive X-ray spectroscopy (EDS).

\section{Results and Discussion}

\subsection{Microstructure}

Figure 1 shows the backscattered electron image of a transverse section of a laser-clad track. A dense cladding with a defect-free metallurgical bonded interface with the substrate was obtained. A clear boundary existed between the substrate and the clad layer. The results of an EDS analysis across the clad-layer and the substrate (Fig. 2) show that a dilution zone of thickness of about $150 \mu \mathrm{m}$ formed at the interface region. In this case, the dilution zone is defined as the region where the amount of inter-diffusion of elements exceeded 10 mass\%. Beyond this zone, the compositional gradient was sharply reduced, which indicates that the mixing of the cladding material, i.e. aluminium with the substrate material was not serious. The presence of about 5 mass $\% \mathrm{Mg}$ in the entire clad-layer is considered to be due to the high diffusion rate of magnesium in aluminium. This result is similar to that obtained for the study of the laser cladding of an $\mathrm{Al}-\mathrm{Si}$ eutectic alloy on a magnesium composite, ${ }^{3)}$ where the main dilution effect was confined to the interface region. This is also in agreement with many previous studies that show strong convection currents in the laser-melt pool might

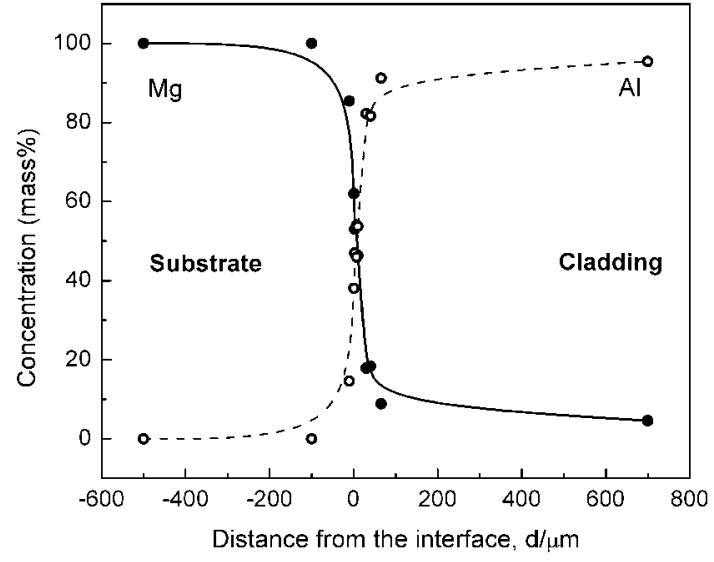

Fig. 2 An EDS analysis of $\mathrm{Mg}$ and $\mathrm{Al}$ profiles across the laser-cladding.

not be sufficient for achieving a complete chemical and structural homogenised structure. ${ }^{8-10)}$

Figure 3 shows the microstructure of a transverse crosssection of a laser-clad track. Towards the surface, the microstructure consists mainly of fine equiaxed $\alpha-\mathrm{Al}$ dendrites (Fig. 3(a)), and only a relatively small amount of eutectic phase present at interdendritic regions. While moving towards the substrate, the amount of eutectic phase increases (Fig. 3(b)). Near the bottom of the laser-cladding, the microstructure was dominated by a eutectic phase (Fig. 3(c)). A closer examination of the interface between the substrate and the clad-layer shows a continuous growth of a cellular band structure (Fig. 3(d)), and the growth direction was found to be towards the substrate. This is quite different from the epitaxial growth normally found in laser cladding. To confirm whether the cellular growth is continuous along the track of the laser-clad, a longitudinal section of the specimen was prepared. Figure 4 clearly illustrates that a continuous band of cellular structure existed along the interface of the laser-clad. The figure also shows a band of fine eutectic phase is present between the substrate and the cellular layer. A high magnification image of the region ahead of the solidification front of the substrate clearly shows the presence of the cellular structure and a band of fine eutectic structures (Fig. 5). In fact, such a backward growth of cellular structure can be found in the results of the study of Ignat $^{7)}$ and Miyamoto ${ }^{11)}$ on laser cladding of $\mathrm{Al}$ on $\mathrm{Mg}$ and $\mathrm{Cu}$ on $\mathrm{Al}$ respectively, but unfortunately the phenomenon was not discussed. An XRD analysis was conducted to determine the various phases present at the interface region between the substrate and the cellular layer. The results show that intermetallic phases, $\beta\left(\mathrm{Mg}_{2} \mathrm{Al}_{3}\right), \beta^{\prime}\left(\mathrm{Mg}_{0.42} \mathrm{Al}_{0.58}\right)$ and $\gamma$ $\left(\mathrm{Mg}_{17} \mathrm{Al}_{12}\right)$, are present (Fig. 6). Based on the results of the $\mathrm{XRD}$ analysis and the metallurgical examination, a schematic diagram is presented in Fig. 7 summing up the major phases present across the laser-clad track. Referring to this figure, the narrow band of $(\beta+\gamma)$ eutectic and the $\beta$-cellular layer formed ahead of the substrate interface is considered to be undesirable. This is because these two intermetallics are brittle phases, ${ }^{12,13)}$ and would not be able to accommodate high stresses in service. The following sections will discuss the evolution of the various microstructures across the laserclad track. 

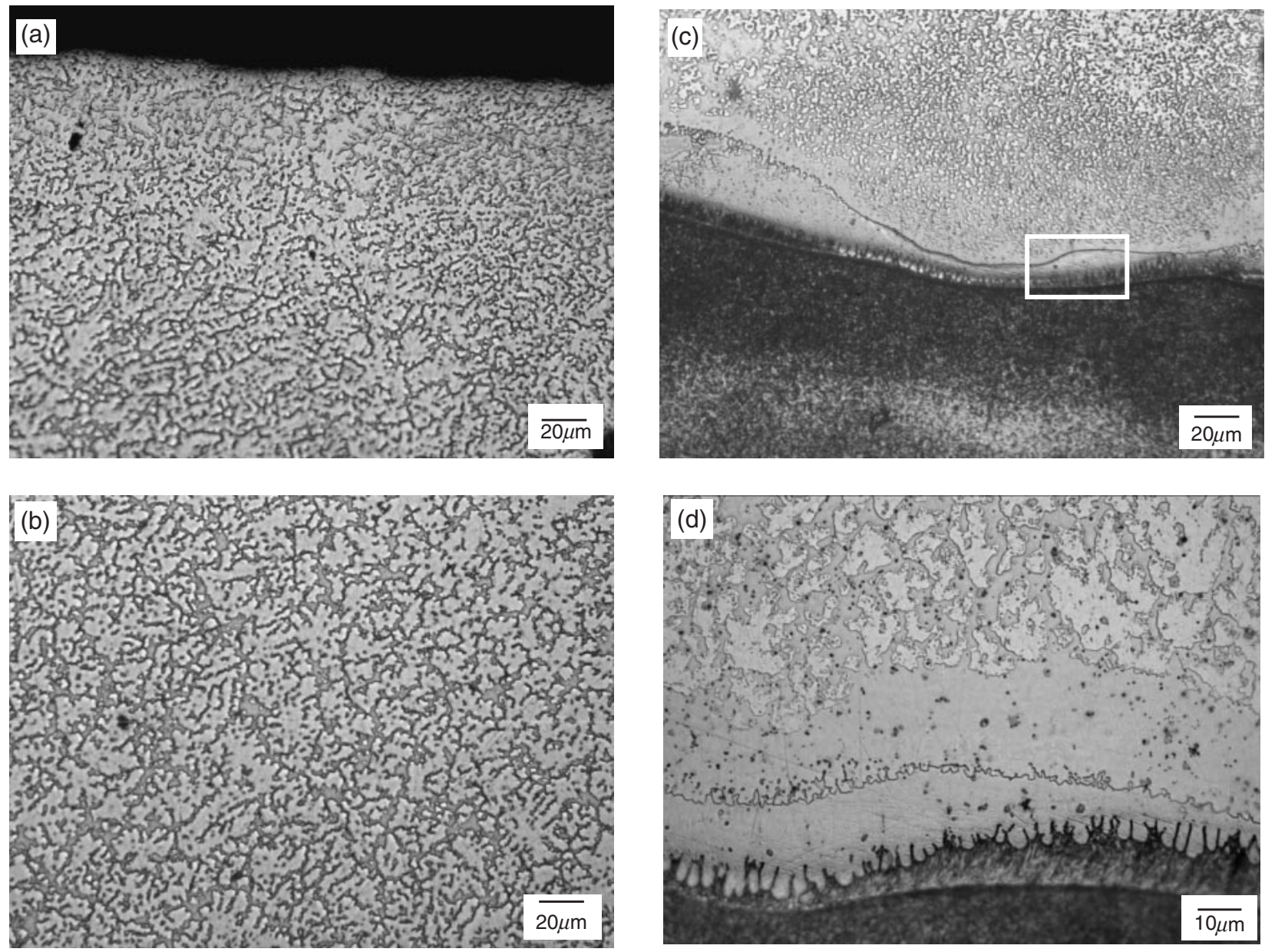

Fig. 3 Microstructure of a laser-cladding: (a) near the top of the track, (b) in the middle, (c) towards the bottom, (d) an enlargement ahead of the substrate interface.

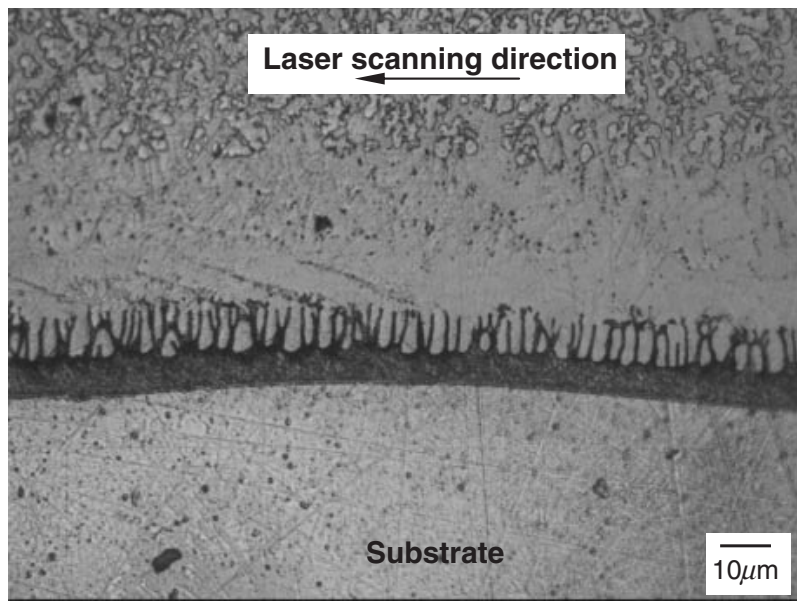

Fig. 4 A longitudinal section showing a continuous band of cellular structure.

\subsection{Magnesium substrate interface}

In the present study, a planar solidification front was observed at the boundary of the magnesium substrate. It is clear that laser cladding conditions would influence the temperature gradient $G$ and the solidification rate $V$ of the molten pool. On the other hand, the composition of the molten pool would determine the magnitude of the freezing

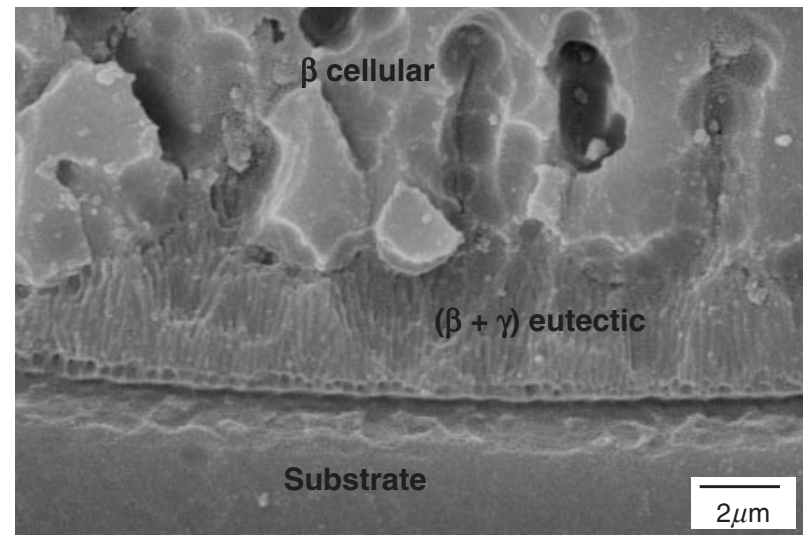

Fig. 5 A SEM micrograph showing the cellular structure and the $(\beta+\gamma)$ eutectic phase formed ahead of the planar solidification front of the substrate.

range, which in turn would affect the type of microstructure formed in the clad-layer. Also, in laser surface melting, the growth velocity $(V)$ of the solid/liquid interface that has the cellular, planar or eutectic morphology can be related to the scanning velocity of the laser beam $\left(V_{S}\right)$ :

$$
V=V_{s} \cdot \cos (\theta)
$$

where $\theta$ is the angle between the vector representing the 


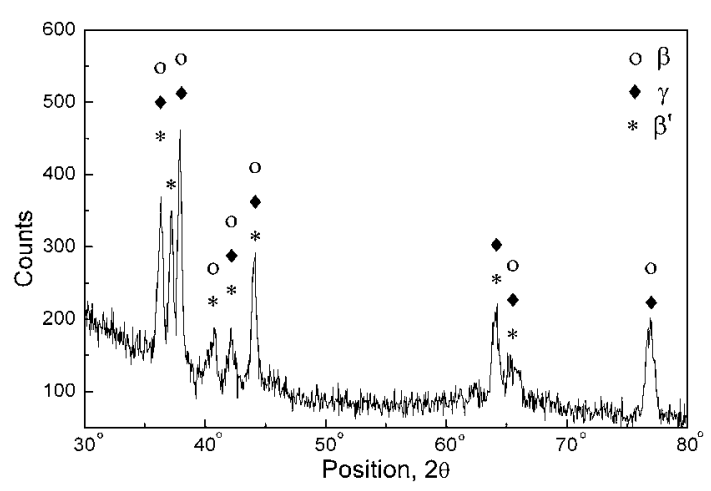

Fig. 6 The results of an x-ray diffraction analysis of the region ahead of the substrate interface that makes up the cellular and the fine eutectic structures.

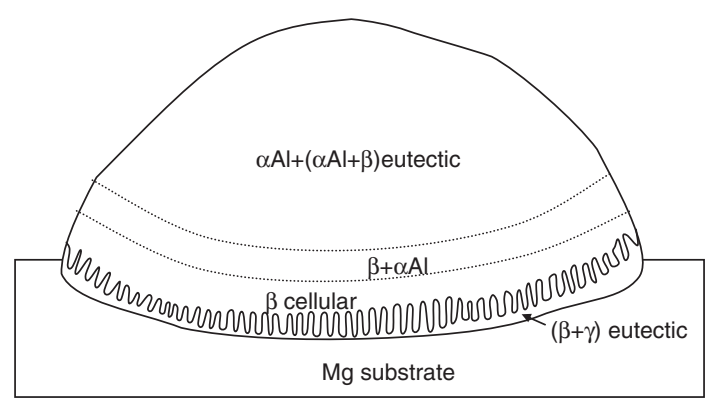

Fig. 7 A schematic diagram showing the major phases present across the laser-clad track (not to scale).

direction of the transverse movement of the substrate and the vector normal to the solid/liquid interface. It is understand that the solidification rate $V$ varies throughout the solidification process from a minimum at the fusion boundary of the substrate (where $\theta$ approaches $90^{\circ}$ ) to a maximum at the surface of the clad-layer (where $\theta$ approaches $0^{\circ}$ ). In the present study, the angle $\theta$ was measured in terms of the orientation of the growth direction of the cellular structure from a longitudinal-section of a laser-clad specimen. From the measurement, an average value of $85.4^{\circ}$ was obtained for 50 cellular stems. The value of $V_{S}$ used in this study was 5 $\mathrm{mm} / \mathrm{s}$. Given these conditions, $V$ was calculated for the magnesium substrate to be $0.4 \mathrm{~mm} / \mathrm{s}$. This solidification rate was found to be relatively small. This agrees with most of the previous studies ${ }^{14-16)}$ in that $V$ was found to be virtually zero at the bottom of the laser-melt pool, and increased to a maximum towards the surface of the melt. Now, because the solidification rate was found to be relatively low at the bottom of the molten zone, the morphology of solidification growth can be determined by the constitutional supercooling theory. ${ }^{17)}$ If the solidification condition prevails that the condition of eq. (2) is met, then the morphology of the solidliquid interface would remain planar; otherwise it would become unstable and the interface may develop into a cellular or dendritic structure. The condition that needs to be satisfied is,

$$
\frac{G}{V}>\frac{m_{0} C_{0}\left(k_{0}-1\right)}{k_{0} D_{L}}
$$

where $m_{0}$ is the slope of the liquidus line, $C_{0}$ is the alloy constitution, $k_{0}$ is the distribution coefficient, and $D_{L}$ is the diffusion coefficient.

According to eq. (2), the lowest critical temperature gradient $\left(G_{c}\right)$ in the liquid to ensure the stable growth of a planar interface was calculated. In the calculation, an alloy with a composition of $\mathrm{Mg}-10$ mass\% Al was assumed, this was based on the average composition profile (Fig. 5) measured ahead of the magnesium interface.

$$
\begin{aligned}
G_{C} & =\frac{m_{0} C_{0}\left(k_{0}-1\right) \mathrm{V}}{k_{0} D_{L}} \\
& =\frac{-3.75 \times 10 \times(0.1-1)}{0.3 \times 1.8 \times 10^{-9}}=250 \mathrm{~K} / \mathrm{cm}
\end{aligned}
$$

Since this calculated value for planar growth is much lower than the value of $G$ that normal exists in laser cladding $\left(>1 \times 10^{3} \mathrm{~K} / \mathrm{cm}\right)$, a planar solidification front is therefore expected for the present study. And this agrees with the experimental result obtained, namely that a planar growth front was observed at the boundary of the magnesium substrate.

\subsection{The cellular growth}

Ahead of the planar growth front of the magnesium substrate, there was a narrow eutectic band zone together with a layer of cellular structure whose direction of growth is towards the magnesium substrate. To explain the development of microstructure ahead of the magnesium substrate interface, the information about the composition profile (Fig. 2) together with the binary Al-Mg phase diagram, were utilised. Based on this information, isotherms which match the corresponding phase field of the phase diagram (Fig. 8) were created. According to the results, there is a low melting point $(\beta+\gamma)$ eutectic phase lying ahead of the magnesium planar interface. This is believed to be due to the fact that the fast growing solidification front was moving from the top side of the molten pool, while the planar solidification front of the magnesium substrate was moving extremely slowly. As a result, the low melting point eutectic phase was trapped just ahead of the magnesium planar interface.

Regarding the cellular structure, as solidification proceeds towards the bottom of the molten pool, the growth of primary $\beta$ phase occurs, and solute of $\mathrm{Mg}$ is rejected ahead of the solidification front. As a result, constitutional supercooling can occur, and the initial planar interface of $\beta$ phase would become unstable when exposed to a gradient of supercooling, and perturbations would develop. Finally, this leads to the development of a cellular structure of $\beta$ phase with the growing direction towards the solidifying liquid. As was mentioned previously, the presence of the brittle $\beta$ phase is undesirable, and in order to suppress its formation, it is necessary to establish a solidification condition that favours the epitaxial growth of $\mathrm{Al}$ on $\mathrm{Mg}$.

\subsection{The morphology of $\alpha$-Al dendrite}

It is apparent that in the laser-clad track, no sign of columnar growth of primary $\alpha-\mathrm{Al}$ is found. The $\alpha$-Al dendrites solidified in the form of equiaxed crystals with the interdendritic regions filled with the eutectic phase of $(\alpha-\mathrm{Al}+\beta)$. The reason for this can be explained on the basis of the condition for columnar-toequiaxed transition (CET), which was developed by Hunt. ${ }^{18)}$ 


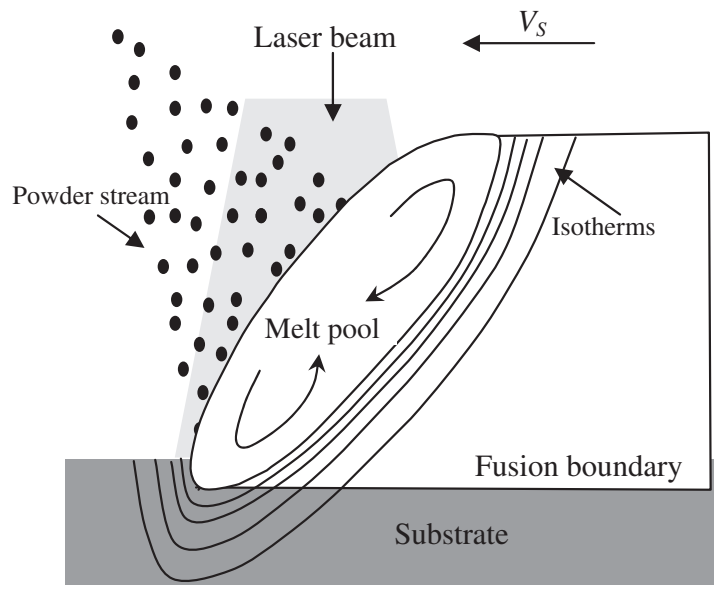

(a)

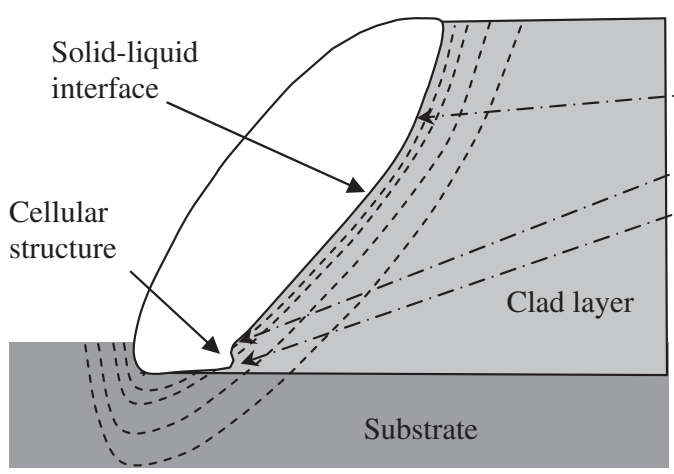

(c)

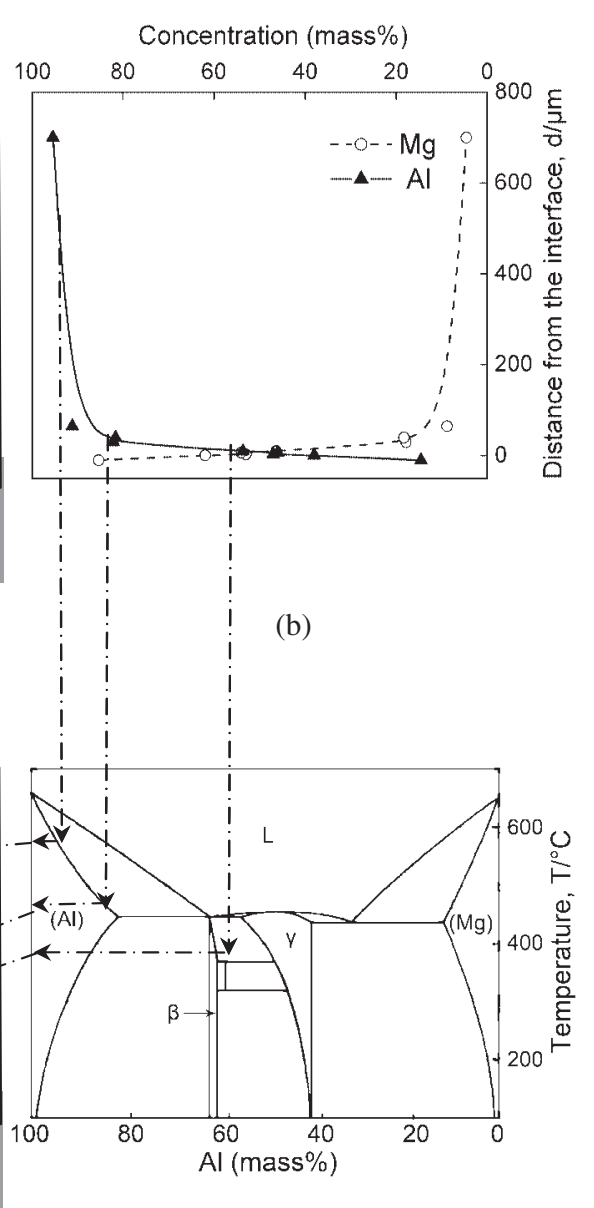

(d)

Fig. 8 The relationships between the composition profile, the Al-Mg phase diagram, and the corresponding microstructure in the laserclad track.

Table 1 Thermophysical parameters for the Al-Mg system.

\begin{tabular}{cccc}
\hline $\begin{array}{c}\text { Slope of liquidus } \\
(\mathrm{k} / \text { wt. pct. })\end{array}$ & $\begin{array}{c}\text { Diffusion coefficient } \\
\left(\mathrm{cm}^{2} / \mathrm{s}\right)\end{array}$ & $\begin{array}{c}\text { Distribution } \\
\text { coefficient }\end{array}$ & $\begin{array}{c}\text { Gibbs-Thomson coefficient } \\
(\mathrm{k} \mathrm{cm})\end{array}$ \\
\hline$-4.8^{*}$ & $9.90 \mathrm{E}-5 \exp (-8610 / \mathrm{T})^{21)}$ & $0.4^{*}$ & $1.3 \mathrm{E}-5^{22)}$ \\
\hline
\end{tabular}

*obtained by calculation

He first developed an analytical model to describe the steadystate conditions for the growth of columnar and equiaxed crystals, which reveals the effects of alloy composition, nucleation density and cooling rate on CET. According to the model, the critical thermal gradient for a fully equiaxed growth can be expressed as:

$$
G<0.617 \cdot N_{0}^{1 / 3}\left\{1-\frac{\left(\Delta T_{N}\right)^{3}}{\left(\Delta T_{C}\right)^{3}}\right\} \cdot \Delta T_{C}
$$

where $N_{0}$ is the total number of heterogeneous substrate particles originally available per unit volume, $\Delta T_{\mathrm{N}}$ is the undercooling at the heterogeneous nucleation temperature. $\Delta T_{\mathrm{C}}$ is the undercooling at the columnar front, which can be expressed as:

$$
\Delta T_{C}=\left(\frac{V C_{0}}{A}\right)^{1 / 2}
$$

where $\mathrm{A}$ is a constant.
Based on this model, the CET curve for Al-10 mass\% $\mathrm{Mg}$ and Al-5 mass\% Mg alloys were determined. These two compositions were selected because the composition gradient measured across the laser-clad track shows that the content of magnesium in the primarily $\alpha$-Al dendrites zone, roughly ranged between 10 mass $\%$ and 5 mass $\%$. In the present work, the value of $N_{0}$ was assumed to be 1000 per cubic millimetre. This was according to the analysis of Lin, ${ }^{19)} \Delta T_{\mathrm{N}}$ was taken to be $0.75 \mathrm{~K}^{18)}$ Other thermophysical parameters used for the calculations of are given in Table 1 . The value of constant $A$ was calculated by combining the KGT model ${ }^{20)}$ and Hunt's analysis. ${ }^{18)}$ The relationship between $\Delta T-V$ was obtained from the KGT model, then according to the equation,

$$
\Delta T=\frac{G D}{V}+\left(\frac{C_{0} V}{A}\right)^{1 / 2}
$$

the value of $A$ was acquired using nonlinear regression analysis of the $\Delta T-V$ relationship. 


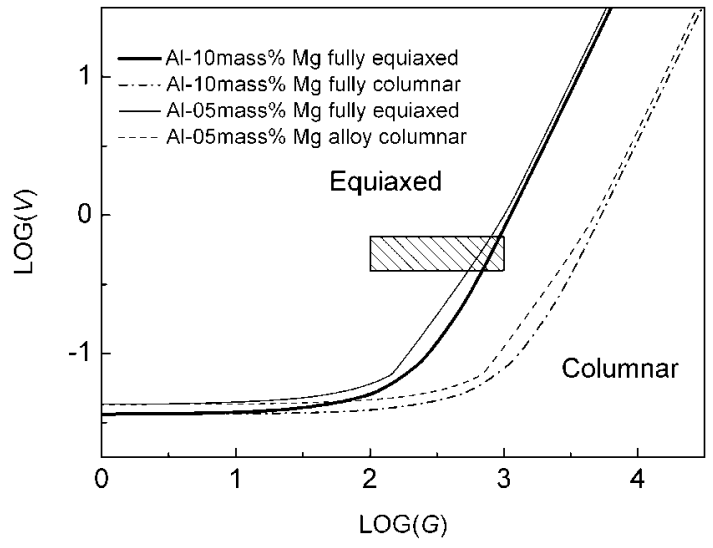

Fig. 9 The predicted regions for columnar crystal growth and equiaxed crystal growth as a function of solidification parameters $G$ and $V$. The shaded area is the experimental condition.

The CET curves for the two alloys were obtained and are presented in Fig. 9. The figure also gives the experimental conditions of the present study. It should be pointed out that, during laser cladding, the temperature gradient decreases continuously, and the solidification velocity increases gradually from the bottom of the molten pool to the top. So the solidification conditions are changing as solidification proceeds and the shaded region in Fig. 9 represents the changes. The predictions show that within the limits of the composition studied and the experimental conditions experienced in the study, the preferred crystal structure for the majority potion of the laser-clad track should be in the form of equiaxed. This is in good agreement with the observed microstructure of the main portion of the laser-clad track.

\section{Conclusions}

Dense aluminium single tracks with a good metallurgical bond were formed on magnesium substrates using the blown powder laser cladding method. A relatively narrow composition diffusion zone was detected at the substrate-clad interface; in the main portion of the clad, an average content of 5 mass $\% \mathrm{Mg}$ was measured. As to the microstructure, the laser-cladding consists primarily of fine dendrites of $\alpha$-Al and $\alpha-\mathrm{Al}+\beta$ eutectic. This was found to be due to the high thermal gradient that existed in the process of laser cladding and the strong tendency of columnar-to-equiaxed transition for Al-Mg alloys. Ahead of the solidification boundary of the substrate, a band of $\beta$ cellular structure was found; the phenomenon was explained in terms of constitutional supercooling. The presence of a continuous band of $\beta$ cellular structure is considered to be undesirable, because it is a brittle phase. With regard to the solidification behaviour of the substrate material, a planar growth interface was obtained. This was found to be due mainly to the low growth rate that was experienced in the magnesium substrate.

\section{Acknowledgements}

The work described in this paper was fully supported by a grant from the Research Grants Council of the Hong Kong Special Administrative Region, China (Project No. PolyU 5312/05E). The authors also thank the Hong Kong Polytechnic University and Northwestern Polytechnical University for providing the research facilities.

\section{REFERENCES}

1) R. Subramanian, S. Sircar and J. Mazumder: J. Mater. Sci. 26 (1991) 951-956.

2) A. A. Wang, S. Sircar and J. Mazumder: J. Mater. Sci. 28 (1993) 51135122.

3) T. M. Yue, A. H. Wang and H. C. Man: Scripta Mater. 40 (1999) 303311.

4) J. E. Gray and B. Luan: J. Alloy. Compd. 336 (2002) 88-113.

5) J. Dutta Majumdar, R. Galun, B. L. Mordike and I. Manna: Mater. Sci. and Eng. A 361 (2003) 119-129.

6) J. Dutta Majumdar, B. Ramesh Chandra, B. L. Mordike, R. Galun and I. Manna: Surface and Coatings Technology 179 (2004) 297-305.

7) S. Ignat, P. Sallamand, D. Grevey and M. Lambertin: Appl. Surf. Sci. 225 (2004) 124-134

8) X. He, B. L. Mordike, N. Pirch and E. W. Kreutz: Lasers in Eng. 4 (1995) 291-316.

9) P. Mohan Raj, S. Sarkar, S. Chakraborty, G. Phanikumar, P. Dutta and K. Chattopadhyay: International Journal of Heat and Fluid Flow 23 (2002) 298-307.

10) N. Chakraborty, D. Chatterjee and S. Chakraborty: Numerical Heat Transfer A 46 (2004) 1009-1032.

11) I. Miyamoto, S, Fujimori and K. Itakura: ICALEO “97”, ed. by R. Fabbro, A, Karr and A. Matsunawa, (Laser Institute of America, 1997) pp. F1-F10.

12) D. P. Shashkov: Metallurg 39 (1995) 21-25.

13) S. Kleiner, O. Beffort, A. Wahlen and P. J. Uggowitzer: Journal of Light Metals 2 (2002) 277-280.

14) W. Kurz and R. Trivedi: Trans. ASME 114 (1992) 450-458.

15) Z. X. Liu: Ph.D. dissertation, Northwestern Polytechnical University, China, 2003.

16) Y. P. Su: Ph.D. dissertation, Northwestern Polytechnical University, China, 2004.

17) W. A. Tiller, K. A. Jackson, J. W. Rutter and B. Chalmers: Acta Metall. 1 (1953) 428-437.

18) J. D. Hunt: Materials Science and Engineering 65 (1984) 75-83.

19) X. Lin, Y. M. Li, M. Wang, L. P. Feng, J. Chen and W. D. Huang: Science in China (Series E) 46 (2003) 475-489.

20) W. Kurz, B. Giovanola and R. Trivedi: Acta Metall. Mater. 34 (1986) 823-830.

21) M. Gündüz and J. D. Hunt: Acta Metall. 37 (1989) 1839-1845.

22) A. S. Yue: Journal of Crystal Growth 42 (1977) 542-546. 